\title{
DYNAMiC ANALYSIS AND MOTiOn CONTROL OF Hydraulic Crane For Men Lifting USing MODELING AND SIMULATIONS
}

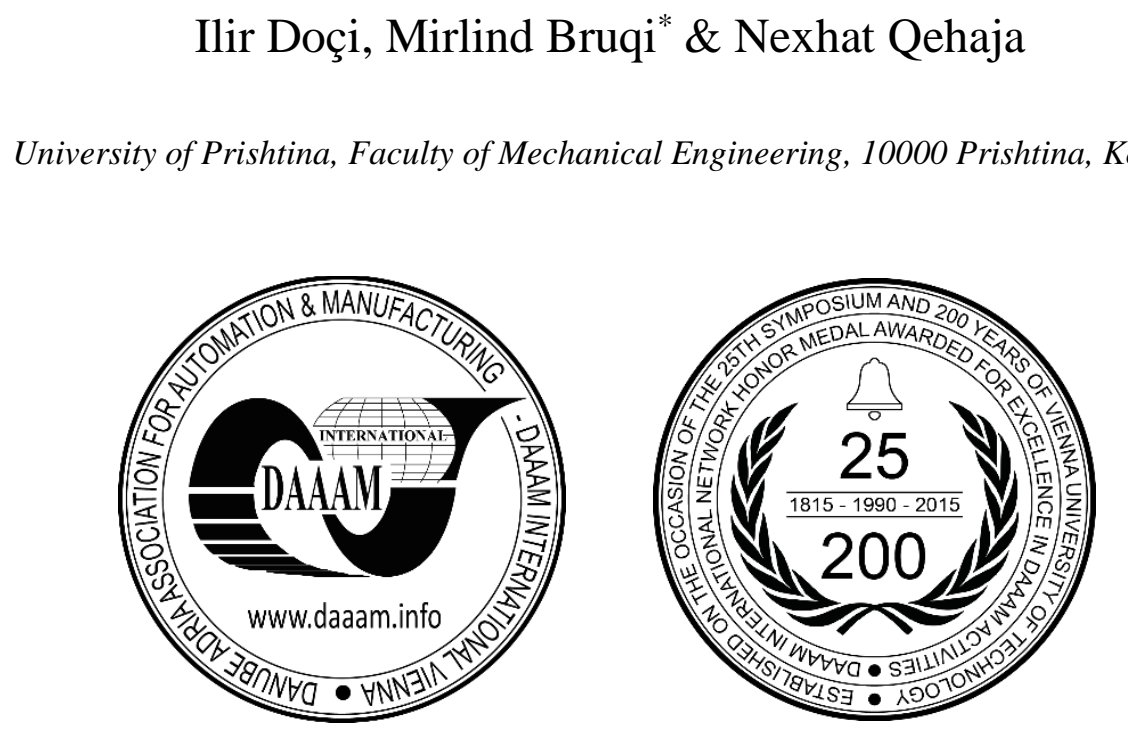

This Publication has to be referred as: Doci, I[lir]; Bruqi, M[irlind] \& Qehaja, N[exhat] (2016). Dynamic Analysis and Motion Control of Hydraulic Crane for Men Lifting Using Modeling and Simulations, Proceedings of the 27th DAAAM International Symposium, pp.0693-0700, B. Katalinic (Ed.), Published by DAAAM International, ISBN 978-3-90273408-2, ISSN 1726-9679, Vienna, Austria

DOI: $10.2507 / 27$ th.daaam.proceedings. 100

\begin{abstract}
This paper deals with modeling and simulation of Hydraulic crane for load lifting in order to determine its dynamics, methods for lifting control and minimization of oscillations. The proposed procedure is modelling of crane with method of schematic design with inerconnected elements that represents crane parts, and its 3-d visualization. Simulations will be planned and applied for lifting motion of Crane's Boom with hangind load. Dynamic analysis will be carried through simulations and solution of Euler differential equations of second order. Diagrams with results of main dynamic and kinematic parameters will be presented for main parts of crane as the solution results of the analyzed system. Based on these results conclusions will be presented. The aim is to find optimal lifting control process and dynamic behavior of crane which is important for motion planning, failure analysis and safety during work. Analysis will be done using modeling and simulations with computer application MapleSim.
\end{abstract}

Keywords: Hydraulic Crane; Men Lifting; Dynamics; Vibrations; Control; modeling; simulations;

\section{Introduction}

Many companies that work with Hydraulic cranes have difficulties dealing with load lifting due to oscillations and swinging of load, which can lead to safety problems. Hydraulic crane taken for study is also known as a Straight Boom Lift, Man Lift, Basket Crane. It is an elevated work platform that consists of a platform or Cabin at the end of a lifting system and is used to lift men and other load. It is important to find optimal procedure to lift the men and load in order to minimize swinging and oscillations. To do this, main kinematic and dynamic parameters of motion must be measured, which is difficult with instrumentation. Modelling and simulations helps determining crane's behavior and search for

* Corresponding author. Tel.: +377 44503 577. E-mail address: mirlind.bruci@uni-pr.edu 
main paramaters on its parts, like: wheels, chasis, boom, cabin, etc. Dynamic and kinematic parameters investigated are: motion length, velocity, acceleration, angular velocity, forces and torque that act in main parts of crane. Model of Hydraulic Crane is designed and modeled with software Maple Sim 6.1 [3]. Model is created based on manufacturer $J L G$ 660SJ (Fig.1) [1]. Main technical data of crane are: Total weight of crane $12519 \mathrm{~kg}$; Max work height $21.3 \mathrm{~m}$; Max carrying load: Capacity: $Q_{\max }=454 \mathrm{~kg}$. Boom lifting speed is $\mathrm{v}_{\mathrm{l}}=0.25 \mathrm{~m} / \mathrm{s}$. (Fig. 1 ).

Until now, authors have studied dynamics of hydraulic cranes, with suggestion of various crane model types [4], [6], [10], multibody dynamics [2], [4], [9], [13], design of crane hydraulics [4], motion control [4], [5], [12], simulation methods [6], [7], [8], [10], analysis approach [2], [5], [9], [12], and results representation [6], [7], [10], with the aim to find best crane models for analysis, search for dynamics of motion, and implement control. In this work, methodology of research is through Model Predictive Control Technology [5] with software, similar to Bond Graphs [6], with the design of schematic algorithm to create model, find differential equations and implement simulations procedure.

Research is in the field of crane dynamics and control and is limited to load lifting analysis and optimization of lifting motion through analysis of results gained through modeling and simulations. Authors approach is determination of crane's motion through dynamic analysis and control of motion in order to improve safety during crane's work.
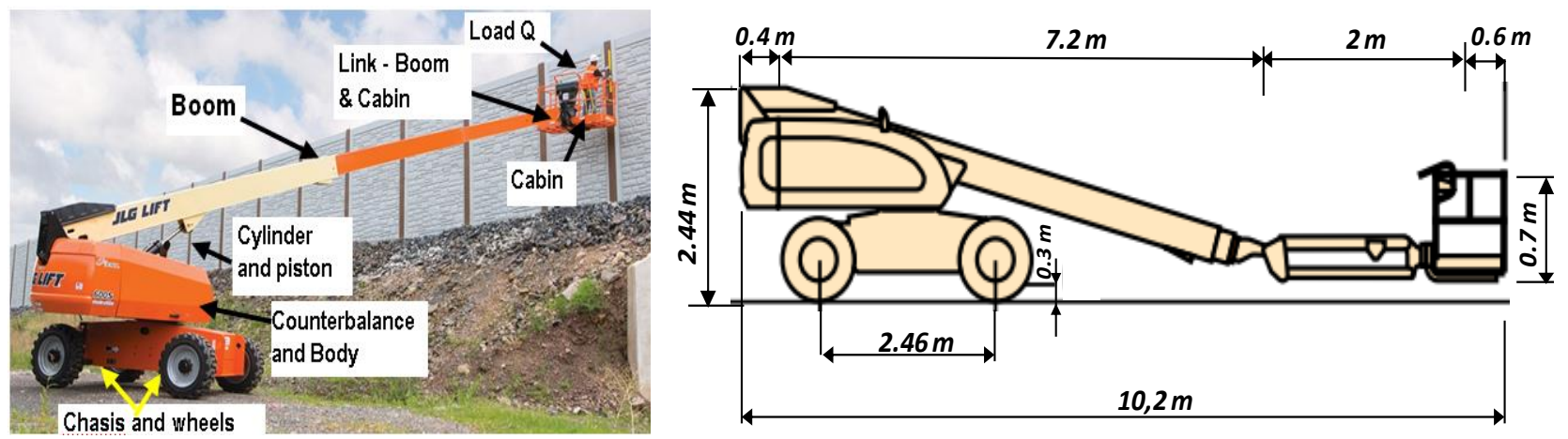

Fig.1. Hydraulic crane studied and its main dimensions [1]

\section{Schematic design of crane model}

In Fig. 2 is presented schematic design and block diagram of Hydraulic crane [1], created with software that enables topological representation, and interconnects related components [3]. Schematic diagram is created for the purpose of analysis, generation of differential equations, applying simulations for control, and getting results.

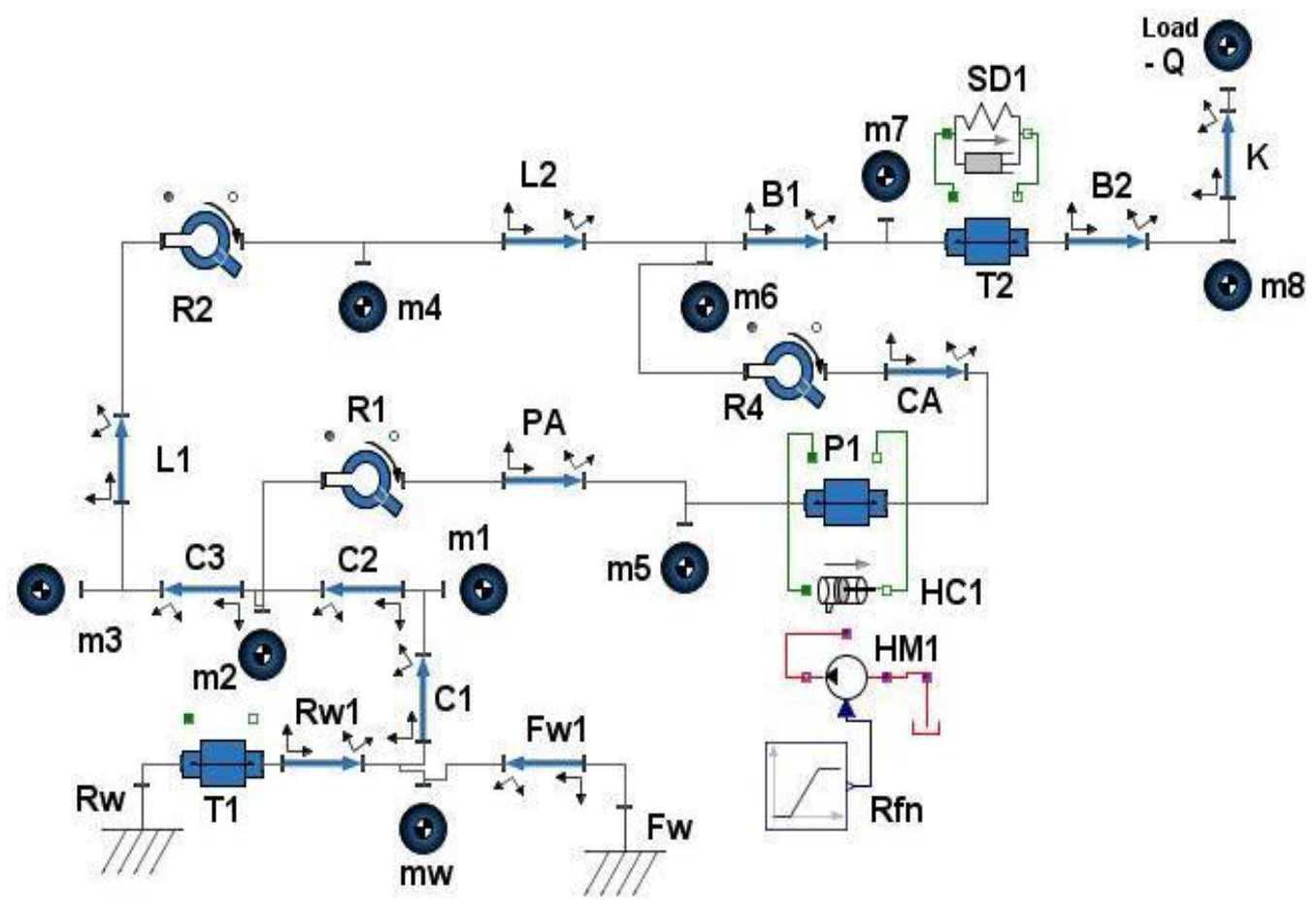

Fig.2. Schematic design (Block Diagram) of hydraulic crane with boom lifting motion 
Block diagram starts from left, with basement of wheels, Chassis and Boom of crane, and continues to the right of scheme where Load Q and cabin K are connected. All crane parts are designed with these elements (Fig.2 \& Fig.3):

- Rigid body frames (bars): Chassis- Rw1 \& Fw1; Link between chassis and Body - C1; Body and Counterbalance C2, C3; Cylinder frames - PA, CA; Link between Body and Boom - L1, Boom - L2 \& B1; Link between Boom and Cabin - B2; Cabin - K. [9]

- Concentrated masses - Chassis mass - $m w$. Body \& Counterbalance masses - $m 1, m 2$, $m 3$; Boom masses- $m 4$, $m 6$, $m 7$; Cylinder mass $-m 5$, Cabin mass- $m 8$, Load- $Q$;

- Fixed Frames - Front wheels - $F w$; Rear Wheels - $R w$, that represents wheels of truck and additional supports;

- Revolute joints - $R 1, R 2, R 3, R 4$;

- Boom lifting piston- P1;

- Hydraulic cylinder for Boom lifting - $\mathrm{HC} 1$;

- Hydraulic motor for Boom Lifting - HM1;

- Translational Joints - In chassis-T1; In Boom - T2;

- Spring and damping element - SD1 - represents oscillations of boom while lifting;

- Ramp function - Rfn - Function of fluid flow values in motor HM1 to implement pressure force in cylinder HC1

In Fig.3. is presented discrete-continuous model of crane used for model view and simulations. This model is 3-D visualization created by software recurring from Schematic design on Fig.2. On this model, simulations will be performed in time frame of $0<\mathrm{t}<15 \mathrm{~s}$. During this simulation time, crane will lift up Boom (L2, B1, B2 elements), Load Q and cabin $\mathrm{K}$.

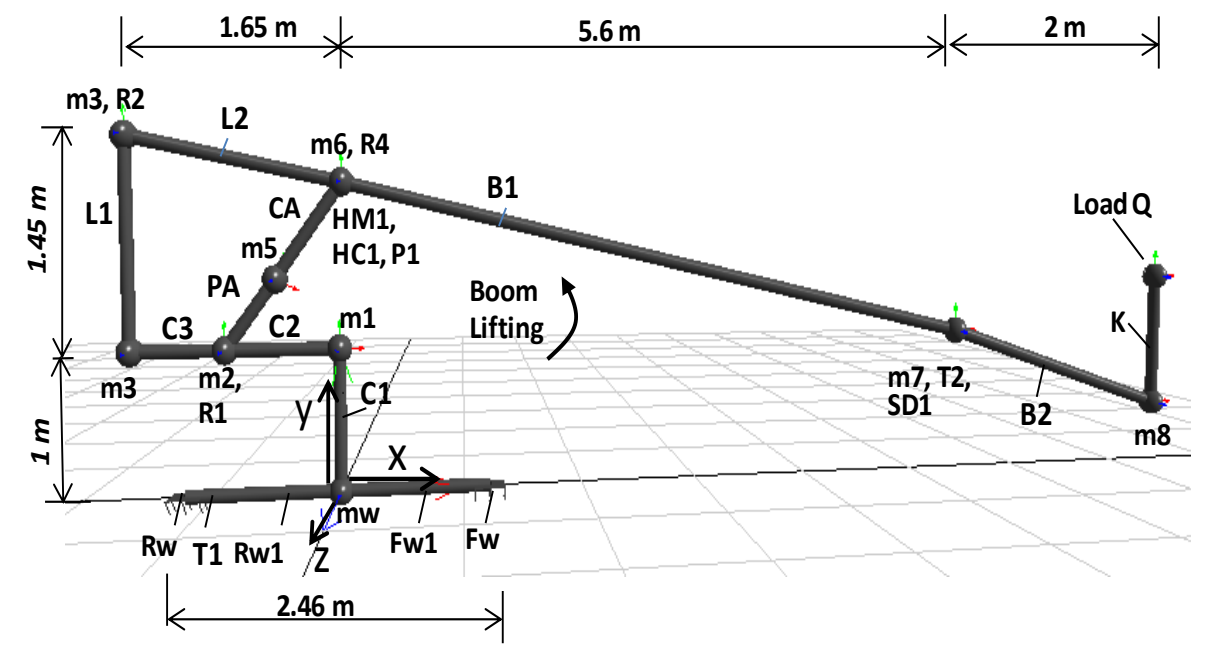

Fig.3. Discrete-continuous model of Hydraulic crane in form of 3-D visualization generated by software [3]

\section{Differential equations of hydraulic crane}

To formulate dynamics of this system, standard Euler-Lagrange methods are applied, by considering the crane as a multi-body system composed by concentrated masses, links and joints. For a controlled system with several degrees of freedom (DOF), the Euler-Lagrange equations are given as [2], [5], [11], [12]:

$$
\frac{d}{d t}\left(\frac{\partial E_{k}}{\partial \dot{q}_{i}}\right)+\frac{\partial E_{p}}{\partial q_{i}}=Q_{i},(\mathrm{i}=1,2 \ldots \mathrm{n})
$$

Where: $\mathrm{q}_{\mathrm{i}}$ - are generalized coordinates for the system with $\mathrm{n}$ degrees of freedom, $\mathrm{E}_{\mathrm{k}}$ is Kinetic Energy, $\mathrm{E}_{\mathrm{p}}$ is Potential energy, $Q$ is the n-vector of external non-conservative forces acting at joints. Kinetic energy for mechanical systems is in the form:

$$
\mathrm{E}_{\mathrm{k}}(\mathrm{q}, \dot{q})=\frac{1}{2} \dot{q}^{T} \cdot M(q) \cdot \dot{q}
$$

$E_{p}(q)$ - is potential energy that is a function of systems position.

$\mathrm{M}(\mathrm{q})$ - is a symmetric and positive matrix of inertias. [4]

Modern software calculates physical modeled systems through mathematical methods, numeric methods and Finite Elements Method [3],[10]. These calculations are based on Euler-Lagrange Equation (3.1), and forces applied for control of force/moments acting on crane. The modeling result is then an $n$-degree-of-freedom crane model whose position is 
described by generalized coordinates $\mathbf{q}=\left[\begin{array}{lll}q_{1} & \ldots & q_{1}\end{array}\right]^{\mathrm{T}}$, and which is enforced, in addition to the applied forces, by $m$ actuator forces/moments $\mathbf{u}=\left[\begin{array}{lll}u_{1} \ldots u_{m}\end{array}\right]^{\mathrm{T}}$, where $\mathrm{m}<\mathrm{n}$ [2]. The crane dynamic equations can be written in the following second order differential equation:

$$
M(q) \cdot \ddot{q}+C(q, \dot{q}) \dot{q}+\frac{\partial E_{p}}{\partial q}=Q(q, \dot{q})-B^{T} u
$$

where $\mathbf{M}$ is the $n x n$ generalized mass matrix, $C(q, \dot{q})$ is $n x n$ matrix of Corriolis Forces, $\partial E_{p} / \partial E_{q}$ is the vector of gravity, $\mathbf{Q}$ is $n$-vector of generalized applied forces, and $\mathbf{B}^{\mathbf{T}}$ is the $n x m$ matrix of influence of control inputs $\mathbf{u}$ on the generalized actuating force vector $\mathbf{f}_{\mathbf{u}}=-\mathbf{B}^{T} \mathbf{u}$. [2]

After design and testing of model, Software Maplesim has powerful module for symbolic generation of differential equations. There are 8 DOF from crane model (Fig.3), which gives 8 differential equations. Variables in differential equations are:

$\boldsymbol{P 1} \boldsymbol{F}(\boldsymbol{t})$ - force in axes direction in piston P1 shown as translational joint ; P1_F2( $(\boldsymbol{t})$ - force in piston P1 in direction of y; $\boldsymbol{T} 2 \_\boldsymbol{F}(\boldsymbol{t})$ - force in translation Joint T2 in Boom B1; $\boldsymbol{T} 2 \_s(\boldsymbol{t})$ - motion in axe of translation Joint T2 in Boom- B1; $\boldsymbol{y}(\boldsymbol{t})$ - variable of flow in cylinder HC1 implemented through ramp function RFn; $\boldsymbol{H C 1} \boldsymbol{s}_{-}$rel $(\boldsymbol{t})$ - Relative length of cylinder $\mathrm{HC}$; $\boldsymbol{R} \mathbf{1} \_\boldsymbol{\theta}(\boldsymbol{t})$ - Rotation of Revolute joint R1 around its axis (z), (Euler Angles); $\boldsymbol{R} \boldsymbol{2} \_\boldsymbol{\theta}(\boldsymbol{t})$ - Rotation of Revolute joint $\mathrm{R} 2$ around its axis $(\mathrm{z})$.

\subsection{Differential equations}

8 Differential equations that represent boom lifting of crane are:

$$
\begin{aligned}
& -\mathrm{T} 2 \_\mathrm{F}(\mathrm{t})-60000 \cdot \mathrm{T} 2 \_\mathrm{s}(\mathrm{t})-2000 \cdot\left(\frac{d}{d t} \mathrm{~T} 2 \_s(\mathrm{t})\right)=0 \\
& -554 \cdot\left(\frac{d}{d t} \mathrm{R} 2 \_\theta(\mathrm{t})\right)^{2} \cdot \mathrm{T} 2 \_\mathrm{s}(\mathrm{t})+654 \cdot\left(\frac{d}{d t} \mathrm{R} 2 \_\theta(\mathrm{t})\right)^{2}+554 \cdot \frac{d}{d t}\left(\frac{d}{d t} \mathrm{~T} 2 \_\mathrm{s}(\mathrm{t})\right)+\frac{50137}{10} \cdot \frac{d}{d t}\left(\frac{d}{d t} \mathrm{R} 2 \_\theta(\mathrm{t})\right)+ \\
& +\frac{271737}{10} \cdot \cos \left(\mathrm{R} 2 \_\theta(\mathrm{t})\right)-\mathrm{T} 2 \_\mathrm{F}(\mathrm{t})=0 \\
& -\frac{41}{100}+\frac{33}{20} \cdot \cos \left(\mathrm{R} 2 \_\theta(\mathrm{t})\right) \cdot \cos \left(\mathrm{R} 1 \_\theta(\mathrm{t})\right)-\frac{3}{10} \cdot \cos \left(\mathrm{R} 2 \_\theta(\mathrm{t})\right) \cdot \sin \left(\mathrm{R} 1 \_\theta(\mathrm{t})\right)+\frac{3}{10} \cdot \sin \left(\mathrm{R} 2 \_\theta(\mathrm{t})\right) \\
& \cdot \cos \left(\mathrm{R} 1 \_\theta(\mathrm{t})\right)+ \\
& +\frac{33}{20} \cdot \sin \left(\mathrm{R} 2 \_\theta(\mathrm{t})\right) \cdot \sin \left(\mathrm{R} 1 \_\theta(\mathrm{t})\right)-\frac{18}{25} \cdot \cos \left(\mathrm{R} 1 \_\theta(\mathrm{t})\right)+\frac{29}{20} \cdot \sin \left(\mathrm{R} 1 \_\theta(\mathrm{t})\right)=0 \\
& \frac{8829}{25} \cdot \cos \left(\mathrm{R} 1 \_\theta(\mathrm{t})\right)-\frac{5886}{5} \cdot \sin \left(\mathrm{R} 1 \_\theta(\mathrm{t})\right)+\frac{784801}{10000} \cdot \frac{d}{d t}\left(\frac{d}{d t} \mathrm{R} 1 \_\theta(\mathrm{t})\right)+\frac{29}{20} \cdot \sin \left(\mathrm{R} 1 \_\theta(\mathrm{t})\right)-\frac{18}{25} \cdot \sin \left(\mathrm{R} 1 \_\theta(\mathrm{t})\right) \\
& \cdot \mathrm{P} 1 \_\mathrm{F} 2(\mathrm{t})-\frac{18}{25} \cdot \cos \left(\mathrm{R} 1 \_\theta(\mathrm{t})\right) \cdot \mathrm{P} 1 \_\mathrm{F}(\mathrm{t})-\frac{29}{20} \cdot \cos \left(\mathrm{R} 1 \_\theta(\mathrm{t})\right) \cdot \mathrm{P} 1 \_\mathrm{F} 2(\mathrm{t})+\frac{33}{20} \cdot \cos \left(\mathrm{R} 2 \_\theta(\mathrm{t})\right) \cdot \\
& \cos \left(\mathrm{R} 1 \_\theta(\mathrm{t})\right) \cdot \mathrm{P} 1 \_\mathrm{F}(\mathrm{t})+\frac{33}{20} \cdot \cos \left(\mathrm{R} 2 \_\theta(\mathrm{t})\right) \cdot \sin \left(\mathrm{R} 1 \_\theta(\mathrm{t})\right) \cdot \mathrm{P} 1 \_\mathrm{F} 2(\mathrm{t})+\frac{3}{10} \cdot \sin \left(\mathrm{R} 2 \_\theta(\mathrm{t})\right) \cdot \cos \left(\mathrm{R} 1 \_\theta(\mathrm{t})\right) \\
& \cdot \mathrm{P} 1 \_\mathrm{F}(\mathrm{t})+\frac{3}{10} \cdot \sin \left(\mathrm{R} 2 \_\theta(\mathrm{t})\right) \cdot \sin \left(\mathrm{R} 1 \_\theta(\mathrm{t})\right) \cdot \mathrm{P} 1 \_\mathrm{F} 2(\mathrm{t})-\frac{33}{20} \cdot \sin \left(\mathrm{R} 2 \_\theta(\mathrm{t})\right) \cdot \cos \left(\mathrm{R} 1 \_\theta(\mathrm{t})\right) \cdot \\
& \mathrm{P} 1 \_\mathrm{F} 2(\mathrm{t})+\frac{33}{20} \cdot \sin \left(\mathrm{R} 2 \_\theta(\mathrm{t})\right) \cdot \sin \left(\mathrm{R} 1 \_\theta(\mathrm{t})\right) \cdot \mathrm{P} 1 \_\mathrm{F}(\mathrm{t})+\frac{3}{10} \cdot \cos \left(\mathrm{R} 2 \_\theta(\mathrm{t})\right) \cdot \cos \left(\mathrm{R} 1 \_\theta(\mathrm{t})\right) \cdot \mathrm{P} 1 \_\mathrm{F} 2(\mathrm{t})-\frac{3}{10} \cdot \\
& \cos \left(\mathrm{R} 2 \_\theta(\mathrm{t})\right) \cdot \sin \left(\mathrm{R} 1 \_\theta(\mathrm{t})\right) \cdot \mathrm{P} 1 \_\mathrm{F}(\mathrm{t})=0 \\
& \frac{142624647}{1000} \cdot \cos \left(\mathrm{R} 2 \_\theta(\mathrm{t})\right)+\frac{614106}{25} \cdot \sin \left(\mathrm{R} 2 \_\theta(\mathrm{t})\right)+1108 \cdot \mathrm{T} 2 \_\mathrm{s}(\mathrm{t}) \cdot\left(\frac{d}{d t} \mathrm{~T} 2 \_\mathrm{s}(\mathrm{t})\right) \\
& \cdot\left(\frac{d}{d t} \mathrm{R} 2 \_\theta(\mathrm{t})\right)+\frac{50137}{10} \cdot \frac{d}{d t}\left(\frac{d}{d t} \mathrm{~T} 2 \_\mathrm{s}(\mathrm{t})\right)+\frac{204218471}{2000} \cdot \frac{d}{d t}\left(\frac{d}{d t} \mathrm{R} 2 \_\theta(\mathrm{t})\right)-1308 \cdot\left(\frac{d}{d t} \mathrm{~T} 2 \_\mathrm{s}(\mathrm{t})\right) \cdot\left(\frac{d}{d t} \mathrm{R} 2 \_\theta(\mathrm{t})\right)+ \\
& 554 \cdot \mathrm{T} 2 \_\mathrm{s}(\mathrm{t})^{2} \cdot\left(\frac{d}{d t}\left(\frac{d}{d t} \mathrm{R} 2 \_\theta(\mathrm{t})\right)-1308 \cdot \frac{d}{d t}\left(\frac{d}{d t} \mathrm{R} 2 \_\theta(\mathrm{t})\right) \cdot \mathrm{T} 2 \_\mathrm{s}(\mathrm{t})\right)-\frac{271737}{50} \cdot \sin \left(\mathrm{R} 2 \_\theta(\mathrm{t})\right) \cdot \mathrm{T} 2 \_\mathrm{s}(\mathrm{t})-\frac{33}{20} \text {. } \\
& \cos \left(\mathrm{R} 2 \_\theta(\mathrm{t})\right) \cdot \sin \left(\mathrm{R} 1 \_\theta(\mathrm{t})\right) \cdot \mathrm{P} 1 \_\mathrm{F}(\mathrm{t})-\frac{33}{20} \cdot \cos \left(\mathrm{R} 2 \_\theta(\mathrm{t})\right) \cdot \sin \left(\mathrm{R} 1 \_\theta(\mathrm{t})\right) \cdot \mathrm{P} 1 \_\mathrm{F} 2(\mathrm{t})-\frac{3}{10} \cdot \sin \left(\mathrm{R} 2 \_\theta(\mathrm{t})\right) \\
& \cdot \cos \left(\mathrm{R} 1 \_\theta(\mathrm{t})\right) \cdot \mathrm{P} 1 \_\mathrm{F}(\mathrm{t})+\frac{33}{20} \cdot \sin \left(\mathrm{R} 2 \_\theta(\mathrm{t})\right) \cdot \sin \left(\mathrm{R} 1 \_\theta(\mathrm{t})\right) \cdot \mathrm{P} 1 \_\mathrm{F} 2(\mathrm{t})-\frac{33}{20} \cdot \sin \left(\mathrm{R} 2 \_\theta(\mathrm{t})\right) \cdot \\
& \cos \left(\mathrm{R} 1 \_\theta(\mathrm{t})\right) \cdot \mathrm{P} 1 \_\mathrm{F}(\mathrm{t})-\frac{3}{10} \cdot \cos \left(\mathrm{R} 2 \_\theta(\mathrm{t})\right) \cdot \cos \left(\mathrm{R} 1 \_\theta(\mathrm{t})\right) \cdot \mathrm{P} 1 \_\mathrm{F} 2(\mathrm{t})+\frac{3}{10} \cdot \cos \left(\mathrm{R} 2 \_\theta(\mathrm{t})\right) \cdot \\
& \sin \left(\mathrm{R} 1 \_\theta(\mathrm{t})\right) \cdot \mathrm{P} 1 \_\mathrm{F}(\mathrm{t})=0
\end{aligned}
$$




$$
\begin{aligned}
& y(t)=\frac{9}{10000}+\left[\begin{array}{cc}
0 & 0<\mathrm{t}<12 \\
-\frac{9}{20000} \cdot \mathrm{t}+\frac{27}{5000} & 12<\mathrm{t}<14 \\
-\frac{9}{20000} & \mathrm{t}>14
\end{array}\right. \\
& \frac{d}{d t} H C 1 \_s \_r e l(t)=50 \cdot y(t) \\
& H C 1 \_s \_r e l(t)=-\frac{3}{10} \cdot \cos \left(\mathrm{R} 1 \_\theta(\mathrm{t})\right) \cdot \cos \left(\mathrm{R} 2 \_\theta(\mathrm{t})\right)-\frac{33}{20} \cdot \cos \left(\mathrm{R} 2 \_\theta(\mathrm{t})\right) \cdot \sin \left(\mathrm{R} 1 \_\theta(\mathrm{t})\right)+\frac{33}{20} \cdot \cos \left(\mathrm{R} 1 \_\theta(\mathrm{t})\right) \\
& \cdot \\
& \cdot \sin \left(\mathrm{R} 2 \_\theta(\mathrm{t})\right)-\frac{3}{10} \cdot \sin \left(\mathrm{R} 1 \_\theta(\mathrm{t})\right) \cdot \sin \left(\mathrm{R} 2 \_\theta(\mathrm{t})\right)-\frac{7}{5}+\frac{29}{20} \cdot \cos \left(\mathrm{R} 1 \_\theta(\mathrm{t})\right)+\frac{18}{25} \cdot \sin \left(\mathrm{R} 1 \_\theta(\mathrm{t})\right)
\end{aligned}
$$

Solution of 8 differential equations will give results, which will be presented in graphical form.

\section{Graphical results for main parts of crane}

Results are achieved after simulations applied on designed system, Fig.2 \& Fig.3. Simulations are planned to reflect real work of crane and boom lifting in order to achieve reliable results. Time of simulation is $\mathrm{t}=15 \mathrm{~s}$. Simulation has three phases [10],[13]:

First phase - Lifting of boom from its start position close to the ground (Fig.3). Lifting speed of boom $\mathrm{v}_{1}=0.25$ $\mathrm{m} / \mathrm{s}$. Time of simulation $0 \mathrm{~s}<\mathrm{t}<12 \mathrm{~s}$. Second phase - Stopping phase of Boom Lifting that usually lasts few seconds, while there is no sudden stop of motion in reality. This phase start after first phase, and lasts 2 seconds, between simulation time $12 \mathrm{~s}<\mathrm{t}<14 \mathrm{~s}$. Third phase - Boom is stopped at highest position and there is no motion, but there are oscillations after stopping. Starts after second phase, lasts between time $14 \mathrm{~s}<\mathrm{t}<15 \mathrm{~s}$, which is end of simulation. It is implemented in order to monitor after motion oscillations.

Simulation of boom lifting is achieved with adjustment of flow rate of fluid in Hydraulic motor HM1 to give enough pressure force on piston $\mathrm{P} 1$ and cylinder $\mathrm{HC1}$, with cross section $\mathrm{A}_{\mathrm{c}}=0.02 \mathrm{~m}^{2}$ and regulate lifting speed. Flow rate is implemented with ramp function Rfn, shown in Fig.4. It starts with $\mathbf{q H M 1}_{\mathbf{H} \mathbf{1}} \mathbf{\mathbf { 0 . 0 0 0 9 }} \mathbf{~ m}^{\mathbf{3}} / \mathbf{s}$ at first simulation phase $(0 \mathrm{~s}<\mathrm{t}$ $<12 \mathrm{~s}$ ), and ends with $\mathbf{q H M 1}_{\mathbf{H}}=\mathbf{0} \mathbf{~ m}^{3} / \mathbf{s}$ at the end of second simulation phase $\mathrm{t}=14 \mathrm{~s}$ (Fig.4). Regulation of process of flow and its values on hydraulic motor HM1 is achieved through numerous tests to implement planned simulation and achieve lifting speed $\mathrm{v}_{1} \approx 0.25 \mathrm{~m} / \mathrm{s}$, in order to get best results with less oscillations [6], [10], [11]. This is the main process of regulation and control in this work. Higher values of qHм1 will give higher speeds which increase oscillations and safety risk, lower values of qHм1 will not lift the maximal load. Other parameters important for regulation and optimized results are for hoisting mechanism [7], [8]. This is for elements SD1 and T2, in order to minimize effect of vibrations which exist in boom during lifting. Spring constant for SD1 is determined as $\mathbf{k}=\mathbf{6 0} \mathbf{k N} / \mathbf{m}$ and Damping constant is $\mathbf{d}=\mathbf{2} \mathbf{~ k N m} / \mathbf{s}$.

Based on model created, differential equations gained, and simulations, results are achieved for main dynamic parameters, shown with their symbols and units as follows: Velocity $v(\mathrm{~m} / \mathrm{s})$, Acceleration a $\left(\mathrm{m} / \mathrm{s}^{2}\right)$, Angular velocity $\omega$ (1/s), Angular acceleration aa (or $\alpha)\left(1 / s^{2}\right)$, Force F (N), Torque T (Nm), Motion or length s (m). [2], [4], [13]

Next will be presented graphical results for main parts of crane, where horizontal axis is time $(\mathrm{t}=0 \ldots 15 \mathrm{~s})$ and vertical axes are corresponding values of dynamic and kinematic parameters. Only most significant graphs will be shown. On these graphs components towards $\mathbf{x}$ axis are shown with index 1, components towards $\mathbf{y}$ axis are shown with index 2 and components towards $\mathbf{z}$ axis are shown with index 3 .

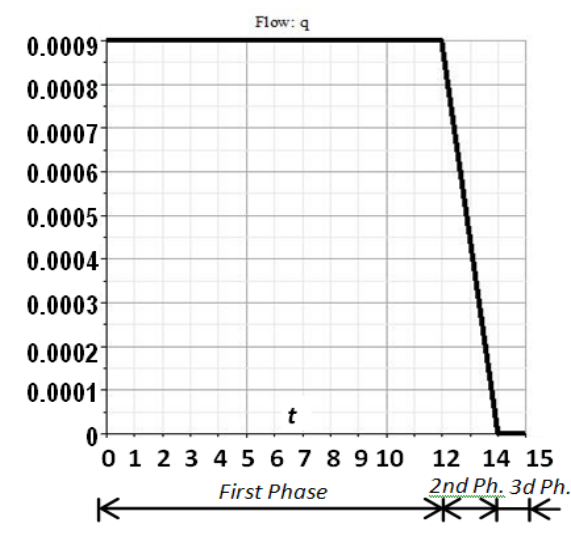

Fig.4. Ramp function Rfn of fluid flow rate qHм1 in motor $\mathrm{HC} 1$

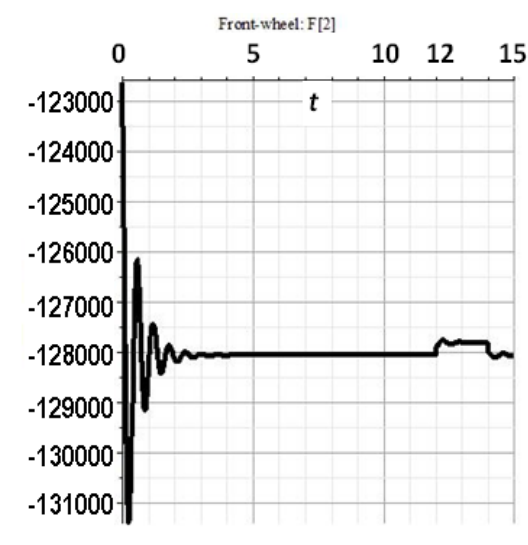

Fig.5. Force component $\mathrm{F}(\mathrm{y})$ or $\mathrm{F}(2)$ in Front wheels (Fw)

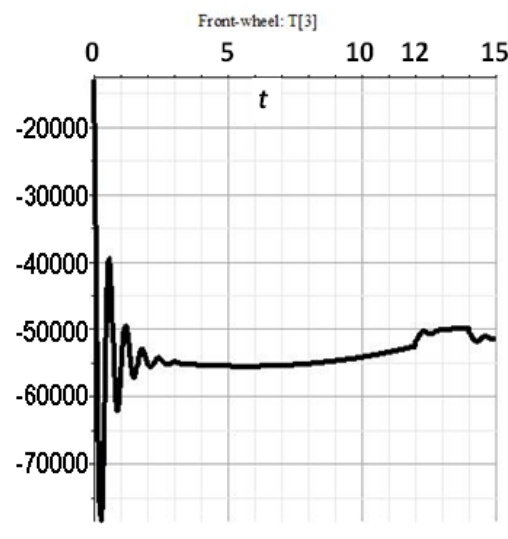

Fig.6. Torque T(z) or (T3) in Front Wheels (Fw) 


\subsection{Results of force and torque in Crane's wheels}

Crane wheels are used for motion of crane and also to provide stability (Fig.1). In schematic diagram (Fig.2) wheels are represented with elements $F w$ and $R w$. In Fig. 5 is shown graph of Componential Force $F(y)$, and in Fig. 6 graph of torque $T(z)$ in Front wheels $-F w$. In Fig.5, Force $F(y)$ is Reaction Force of crane towards $y$ axis. In this case values of other Reaction Forces $\mathrm{F}(1)$ or $\mathrm{F}(\mathrm{x})$ and $\mathrm{F}(3)$ or $\mathrm{F}(\mathrm{z})$ are very small and will not be shown in graphs.

Based on Fig.5, graph of $F(y)$ shows change of curved line, with higher oscillations at the beginning of lifting process $0<\mathrm{t}<4 \mathrm{~s}$, and after lifting stoppage $\mathrm{t}>12$. Oscillations at start are higher than near lifting stop. Max value of Force $\mathrm{F}(\mathrm{y})$ is: $\mathrm{F}_{\mathrm{ymax}}=\left|-1.32 \cdot 10^{5}\right| \mathrm{N}$ at the start of process. Between time $4 \mathrm{~s}<\mathrm{t}<12 \mathrm{~s}$ curve in diagram is less dynamic, almost constant, until $\mathrm{t}>12$ when it again shows small oscillations. Values of $F(x)$ component are small and negligible, up to $\mathrm{F}_{\mathrm{xmax}}=450$ $[\mathrm{N}]$ and not shown in graphs. We can conclude that wheels undergo oscillations that are irregular, with amplitudes that are high at the beginning, up to $\Delta_{\mathrm{F}} \approx 2000 \mathrm{~N}$, but drop fast after 2 seconds to almost 0 , and are small at the stoppage of lifting, $\Delta_{\mathrm{F}} \approx 200 \mathrm{~N}$, giving calm lifting process, starting from $\mathrm{t}=2 \mathrm{~s}$ until the end of lifting. This is the intention of control of lifting motion. In Fig. 6 is graph of Torque T(z) in Front wheels. It has max value: $\mathrm{T}_{\mathrm{zmax}}=|-77000| \mathrm{Nm}$ at the start of process, and drops to medium values of $\mathrm{T}_{\mathrm{zm}}=|-55000| \mathrm{Nm}$ around time $\mathrm{t} \approx 4 \mathrm{~s}$, which gives amplitudes of $\Delta_{\mathrm{T}} \approx 20000$ $\mathrm{Nm}$. Between time $4 \mathrm{~s}<\mathrm{t}<12$ graph drops to almost no oscillations and has curved line. After time $\mathrm{t}>12$ oscillations appear again with smaller dynamic intensity than at the start, with $\Delta_{\mathrm{T}} \approx 5000 \mathrm{Nm}$. This graph concludes again that wheels undergo intensive and irregular oscillations at start, until $\mathrm{t}=3 \mathrm{~s}$, but after that have small oscillations, which shows god results of lifting and control. In Fig. 7 are shown graphical result for Force component $F(y)$ in Rear wheels (Rw). Noticeable is that max value of $F_{y \max }=|-87000| \mathrm{N}$ is smaller than in Front Wheels for about 52\%, due to boom and load position on the side of Front wheels. In Fig.8 is shown value of Torque T(z) in Rear wheels. Conclusion is that dynamics in rear wheels is similar as in front wheels, but with different intensity.

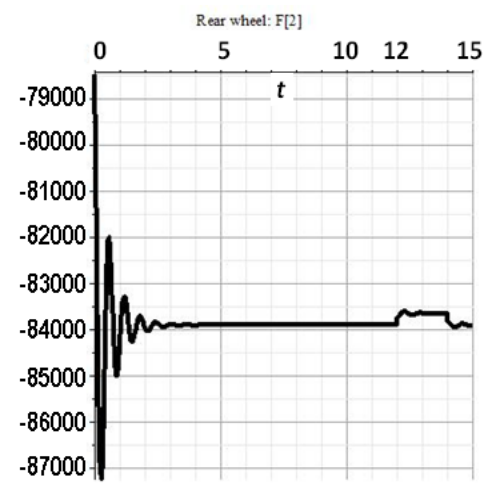

Fig.7. Force component F(y) in Rear wheels (Rw)

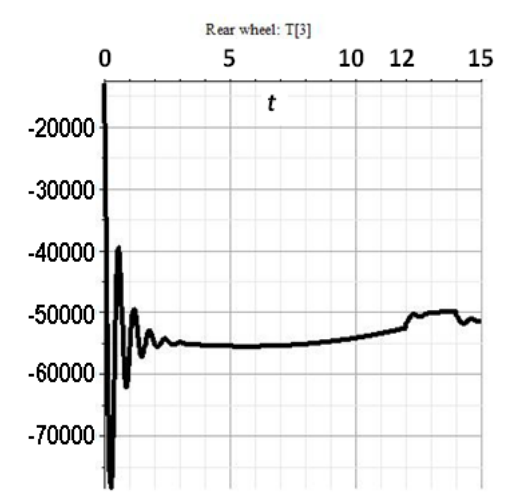

Fig.8. Torque T(z) or (T3) in Rear Wheels (Rw)

\subsection{Results for Crane's Body and Counterbalance}

Body and Counterbalance is rigid part of Crane that connects with Chassis of Crane in bottom, Boom, and Cylinder (Fig.1). In Fig. 2 schematics it consists of elements $C 2, C 3, m 2, m 3$. In Fig. 9 to Fig. 11 are shown graphs of body element C3, Componential Forces $F(x)$ and $F(y)$ and Torque $T(z)$. Between time $4 \mathrm{~s}<\mathrm{t}<12 \mathrm{~s}$ graphs shows inclined curve of forces and torque, due to change of distance of Load $\mathrm{Q}$ from Center of Body during Boom lifting. Conclusions are similar to those of wheels, at the start of lifting there are higher oscillations that drop fast after 3 seconds, and gives calm lifting process up to $t=12$. Between $12 \mathrm{~s}<\mathrm{t}<14 \mathrm{~s}$ there are some small oscillations due to stoppage, but have little effect on Cranes Body.

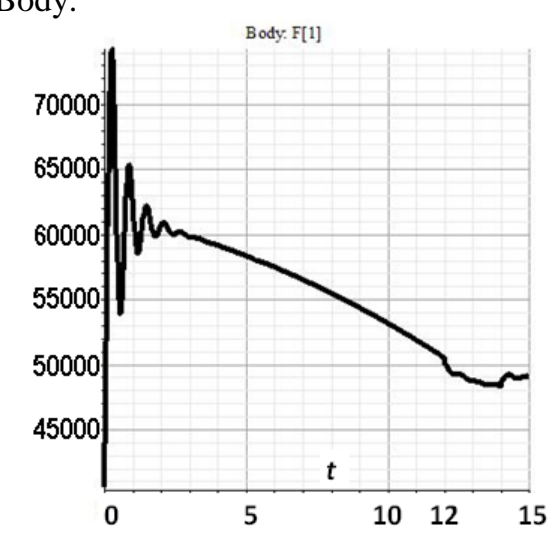

Fig.9. Force components $\mathrm{F}(\mathrm{x})$ in Body

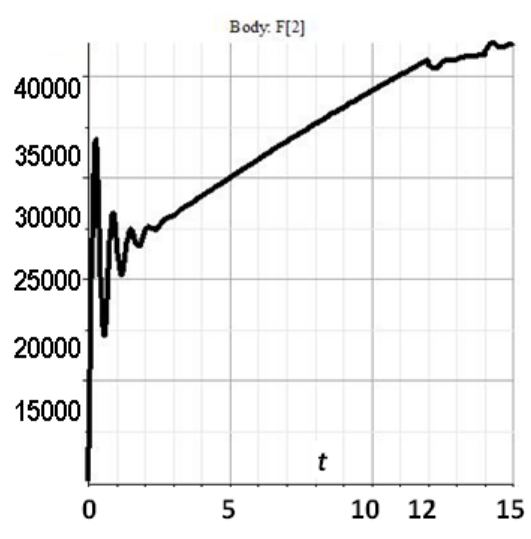

Fig.10. Force components F(y)

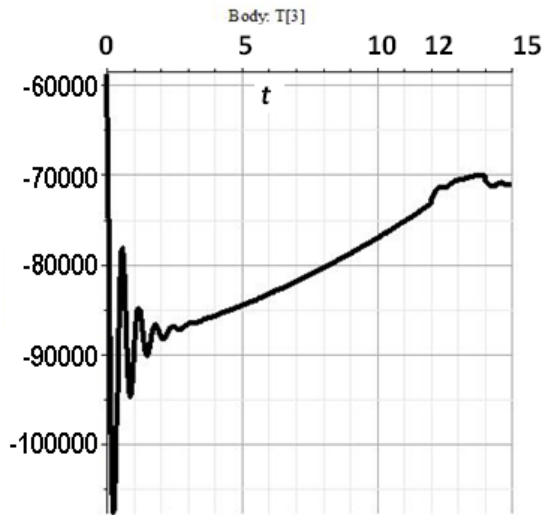

Fig.11. Torque $\mathrm{T}(\mathrm{z})$ 


\subsection{Results for Crane's Boom}

In Fig.12 to Fig.14 are shown graphical results for Lifting Boom element B1 for some main parameters. This is the part that passes the force from cylinder to lift the load $\mathbf{Q}$, and is heavy loaded part. Load Component $\mathrm{F}(\mathrm{x})$ is increasing until $\mathrm{t}=12 \mathrm{~s}$, but has smaller intensity, with no oscillations, and has small effect on Boom. Force component $\mathrm{F}(\mathrm{y})$ and Torque $\mathrm{T}(\mathrm{z})$ have higher intensity, and are dynamic in nature, similar to Conclusions of motion and oscillations for wheels and Crane's Body.

Last Graph, Fig.14, is important kinematic parameter Angular velocity $w(z)$ in Crane's Boom. Between time $1 \mathrm{~s}<\mathrm{t}<12 \mathrm{~s}$ values are almost constant and don't change significantly, then drop down between time $12 \mathrm{~s}<\mathrm{t}<14 \mathrm{~s}$, and have value 0 at time $\mathrm{t}=15 \mathrm{~s}$ due to motion stop. This change corresponds with simulations function, Fig.4.

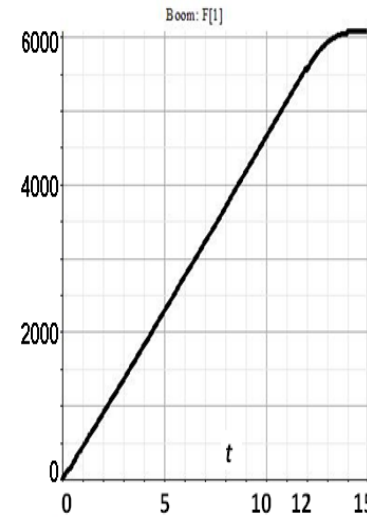

Fig.12. Force components $\mathrm{F}(\mathrm{x})$ and $\mathrm{F}(\mathrm{y})$ in Crane's

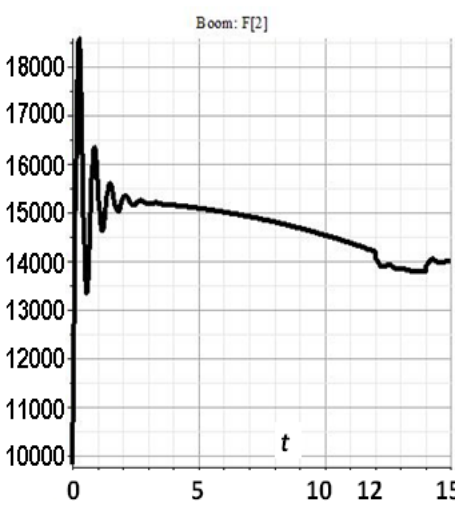

Boom

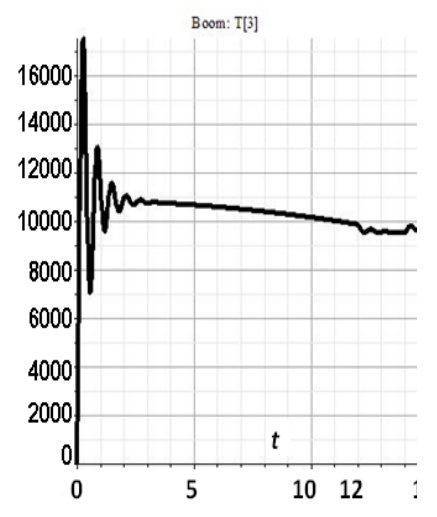

Fig.13. Torque T(z)

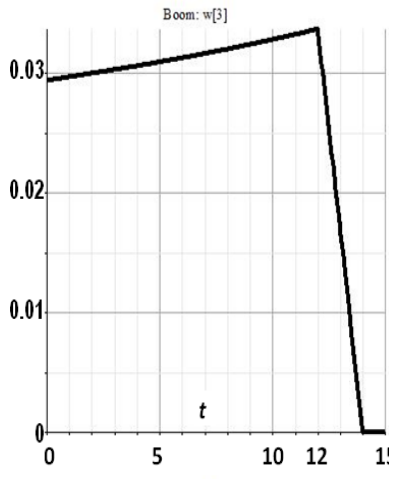

Fig.14. Angular velocity w(z) in Crane's Boom

\subsection{Results for hydraulic cylinder and piston}

In Fig. 15 to Fig.18 are shown graphical results for Hydraulic cylinder HC1 and piston P1. These are parts that give power and motion for boom lifting. Hydraulic motor HM1 transfers flow of fluid qHм1 to Hydraulic Cylinder HC1, which converts to pressure force to piston P1 and thereafter on Crane's Boom - L2 and B1. Based on Fig.15, the form of curve of Pressure Force in Cylinder HC1, as main power force of process, is passed to other parts of crane, similar in dynamic behavior and oscillations. Velocity of piston in Fig.17 corresponds to lifting Ramp function and fluid flow in Fig.4. In Fig.18, force components in piston have similar form as in Fig.15, and as in previous crane parts.

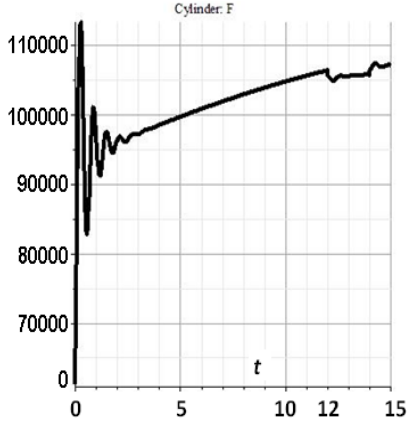

Fig.15. Pressure force in cylinder $\mathrm{HC} 1$

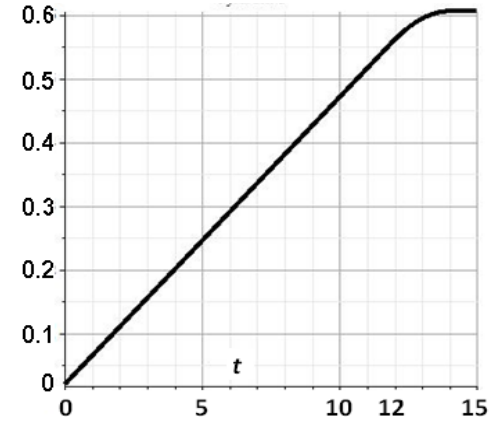

Fig.16. Motion length of piston P1

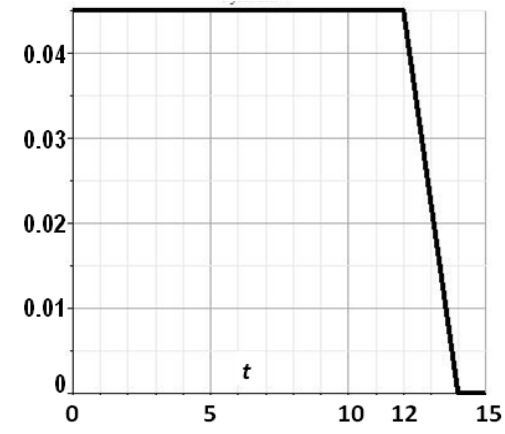

Fig.17. Velocity of piston $\mathrm{P} 1(\mathrm{~m} / \mathrm{s})$
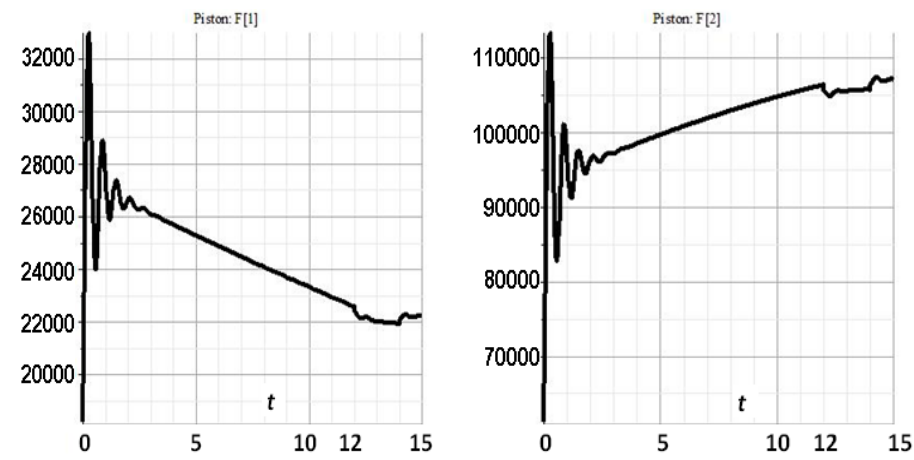

Fig.18. Force components $\mathrm{F}(\mathrm{x})$ and $\mathrm{F}(\mathrm{y})$ in piston $\mathrm{P} 1$ 


\subsection{Results of oscillations for Load $Q$ and cabin $K$}

Load Q is the part being carried by crane, in this case men working and other type of load. Cabin $\mathrm{K}$ with load Q will make oscillations while being lifted. These oscillations influence directly and indirectly other parts of crane. It is important to identify dynamic behavior of load and cabin and minimize their oscillations. In Fig.19 is presented lifting of load from start to end, in unit of meters. The curve increases with very small oscillations. This is a sought result, while load has very little swinging due to regulation of Boom lifting speed. In Fig. 20, component $v(y)$ has high oscillations until $\mathrm{t}=3 \mathrm{~s}$, then is constant up to $t=12 \mathrm{~s}$, with sought value of $\mathrm{v} \approx 0.25 \mathrm{~m} / \mathrm{s}$. After this, they drop to 0 at $\mathrm{t}=14 \mathrm{~s}$, end of lifting. Conclusion is that load Q and Cabin K at the start of lifting have irregular motion with oscillations, which drops after 3 seconds, and remains low until the end of lifting. Fig.21 represents acceleration $a(y)$ of load Q and Cabin K. Graph shows dynamic form with oscillations at the start of lifting $0 \mathrm{~s}<\mathrm{t}<3 \mathrm{~s}$ with higher frequencies and amplitudes, which drop significantly at the end of process. Between time $4 \mathrm{~s}<\mathrm{t}<12 \mathrm{~s}$ acceleration is close to 0 , which concludes that lifting speed is properly regulated close to constant.

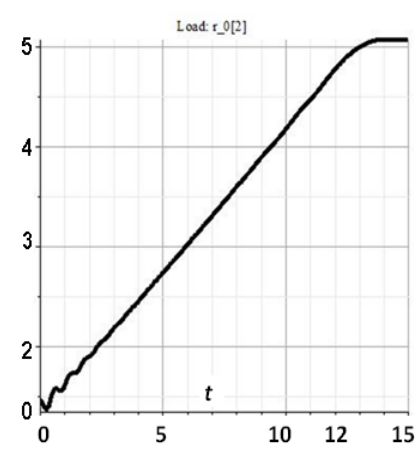

Fig.19. Q and K - Lifting r(y)

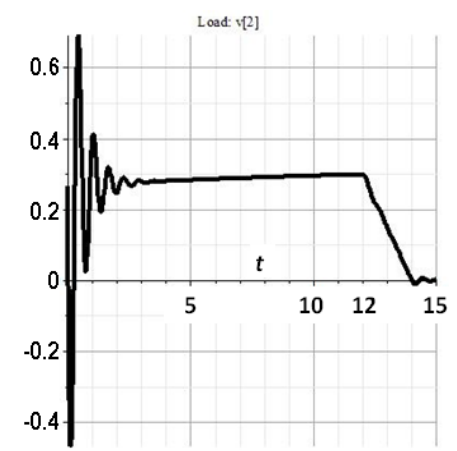

Fig.20. Q and K- Velocity v(y)

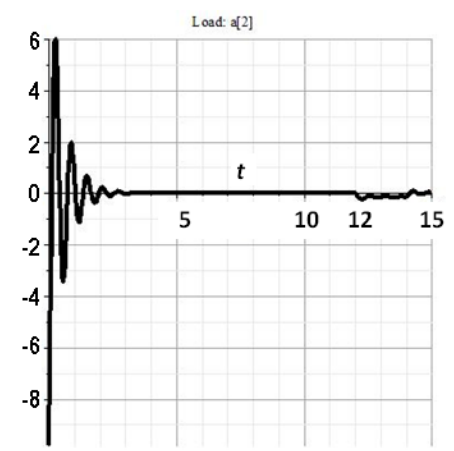

Fig.21. Q and K - Acceleration a(y)

\section{Conclusion}

The main problem during load lifting is oscillations in hydraulic crane as part of dynamic occurrences. In order to control them, it is important to identify them first. To do this we created crane model with schematic design and 3-d visualization, and implemented simulations. Important part of analysis is finding proper simulations plan that reflects real lifting of crane's boom, so that results are reliable. Results are gained for main dynamic parameters and presented in graphical form. From these diagrams can be noticed oscillations in some parts of crane, and mostly with irregular occurrence. They occur in different planes. Oscillations have high intensity at the start of lifting process, almost zero values in the middle of process, and small values at end of process [10], [13]. The intention of research was to minimize oscillations [4], [11]. This was achieved through numerous simulations, in order to find optimal boom lifting, fluid flow in hydraulic motor and accurate spring and dumping constants to minimize load swinging. All this is done to with the aim to optimize the speed of lifting which is main parameter for control and optimization. This work is also important for safety at work, while the load carried are usually humans. It can be used also for further analysis for crane's optimization, and in the future can be used for other work processes of crane, like travel with load.

\section{References}

[1] JLG 660SJ Lift, https://www.jlg.com/en/equipment/engine-powered-boom-lifts/telescopic/600-series.

[2] Garcíaorden, J. Carlos, Goicolea, José M., Cuadrado Javier. (2007). Multibody Dynamics, Computational methods and applications, p.91, 2007 Springer.

[3] MapleSim User Guide. (2014). Maplesoft, a division of Waterloo Maple Inc.

[4] La Hera, P. M. (2011). Dynamics modeling of an electro-hydraulically-actuated system, Umea University.

[5] S. Joe Qin, Badgwell Th.A. (2003). An overview of industrial model predictive control technology, Control Engineering Practice, A Journal of IFAC, ISSN: 0967-0661.

[6] Damica V., Cohodarb M., Kulenovic M. (2013). Modeling and Simulation of Hydraulic Actuated Multibody Systems by Bond Graphs, 24th DAAAM International Symposium on Intelligent Manufacturing and Automation.

[7] Ye F., Qiong W., b, Haiyang Y. (2010). Dynamic Simulation of Hydraulic Truck Crane Hoisting System Based on AMESim, Applied Mechanics and Materials Vols 29-32 (2010) pp 2031-2036.

[8] Yingguang C., Vilmar Æ. and Houxiang Zh., Modelling and simulation of an offshore hydraulic crane, Proceedings 28th European Conference on Modelling and Simulation @ECMS, ISBN: 978-0-9564944-8-1.

[9] Elena S. Gebel, (2015), Mathematical Modeling of Dynamics of Multi-Lever Linkages, 26th DAAAM International Symposium, p. 470-477.

[10] Doçi I., Hamidi B. (2015). Studying rotational motion of Luffing Jib Cranes with maximum load using simulations, International Journal for science, technics and innovations for the industry-MTM 2015; 1(12):20-24.

[11] Vaughan J. (2008). Dynamics and control of mobile cranes, Georgia Institute of Technology.

[12] PARK, Hong Seok \& LE, Ngoc Tran, (2011), A 3d simulation system for mobile harbor crane based on virtual prototyping technology, 22th DAAAM International Symposium, p.35-36.

[13] Doçi I, Buza Sh, Pajaziti A, Cakolli V, (2015), Studying dynamic effects of motion of telpher on console cranes using simulations. Journal of Fundamental Sciences and Applications. Tech-Sys 2015;21(2):337-342. 